\title{
Risk of cervical lesions in high-risk HPV positive women with normal cytology: a retrospective single-center study in China
}

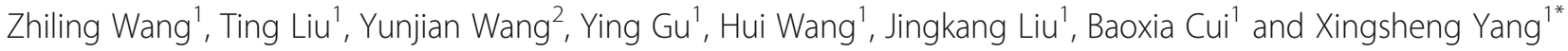

\begin{abstract}
Background: To investigate high-risk HPV (hr-HPV) genotype distributions and the association between hr-HPV infection with severity of the cervical lesions in women with normal cytology.

Methods: In this cross-sectional study, the result of the hr-HPV test and biopsy of colposcopy of women with normal cytology from January 2012 to January 2019 were analyzed. The detection rate of high-grade squamous intraepithelial lesion (HSIL) and cervical cancer were calculated among different hr-HPV genotypes, viral load group, and age groups.

Results: Five thousand eight hundred eighty women were enrolled in this study. Overall, 59.97\% had normal histological results, $19.32 \%$ had HSIL, and $1.07 \%$ had cervical cancer. The detection rate of HSIL or worse (HSIL+) in women with single HPV16(34.00\%), HPV31(27.50\%), HPV33(25.58\%), and HPV52(20.88\%) infection were higher significantly than single HPV18 (15.59\%) infection, respectively. The HSIL+ detection rate between HPV16 single infection and multiple infections (excluding HPV18) was no significant difference (34\% vs $35.47 \%, P=0.638$ ), contrary to HPV18(12.59\% vs 21.67\%, $P=0.022)$. In women without HPV16/18 infections, HSIL+ detection rates for single, double, and triple or more hr-HPV infections were $12.28,20.31$, and $37.50 \%$, the risk of detection of HSIL+ significantly increasing. With the hr-HPV DNA load increases, the risk of detection of HSIL+ $(X 2=91.01, P<0.0001)$ and invasive cervical cancer $(X 2=5.757, P=0.016)$ increase. In age $<30,31-40,41-50,51-60,>60$ group, HSIL+ detection rate were $24.80 \% 、 22.10 \%, 19.59 \%, 14.29$, and $12.61 \%$, respectively.

Conclusion: Women who have normal cytology with HPV 16/18/31/33/52/58 infections, multiple HPV infections and high viral load, have a higher detection rate of HSIL+.
\end{abstract}

Keywords: Uterine cervical neoplasms, Human papillomavirus, Cytology, Viral load

\section{Introduction}

High-risk HPV (hr-HPV) infection is the main etiological factor for the development of cervical neoplasia [1], and routine cervical cancer screening includes hrHPV and cervical cytology tests. Previous randomized controlled trials [2-6] have shown that the strengths of

\footnotetext{
*Correspondence: xingshengyang1964@126.com

'Department of Gynecology, Qilu Hospital of Shandong University, Jinan, China

Full list of author information is available at the end of the article
}

HPV testing are higher sensitivity and negative predictive value than cervical cytology. Given that cumulative incidence of cervical intraepithelial neoplasia (CIN) 3 or cancer 5 years after an HPV-negative test was lower than the risk 3 years after a negative Pap test [6, 7], HPV testing was introduced as the supplementary test in conventional cytology-based screening, even gradually replacing cytology-based screening in primary screening for cervical cancer in some countries [8,9]. As HPV testing is widely used, the optimal clinical management of women

(c) The Author(s). 2020 Open Access This article is licensed under a Creative Commons Attribution 4.0 International License, which permits use, sharing, adaptation, distribution and reproduction in any medium or format, as long as you give appropriate credit to the original author(s) and the source, provide a link to the Creative Commons licence, and indicate if changes were made. The images or other third party material in this article are included in the article's Creative Commons licence, unless indicated otherwise in a credit line to the material. If material is not included in the article's Creative Commons licence and your intended use is not permitted by statutory regulation or exceeds the permitted use, you will need to obtain permission directly from the copyright holder. To view a copy of this licence, visit http://creativecommons.org/licenses/by/4.0/ The Creative Commons Public Domain Dedication waiver (http://creativecommons.org/publicdomain/zero/1.0/) applies to the data made available in this article, unless otherwise stated in a credit line to the data. 
with HPV infection, especially combined normal cytology, remains a challenge. The guidelines recommend managing HPV-positive/cytology-negative results by return testing at 1 year or HPV genotyping for HPV16 and HPV18 [10]. If women have negative cytology but HPV16 and HPV18 infection(s), immediate colposcopy is recommended instead of a 1-year return. HPV16 has higher relevance with cervical lesions than other hr-HPV types $[9,11,12]$. But the reason for choosing HPV18 is uncertain, partly because HPV18 infection has a correlation with cervical adenocarcinoma, which cannot be well detected by cytology [11]. The correlation with other types HPV is not clear yet. What's more, whether viral load can be used as a marker to predict the severity of cervical lesions is currently controversial [13].

Therefore, this study was designed to retrospectively analyze data for up to 7 years, to find the correlation between the severity of cervical lesions and hr-HPV genotypes, viral loads, and ages in HPV-positive/cytology-negative females in China.

\section{Materials and methods Study population}

This study was cross-sectional investigation based on data from women who accepted Thinprep cytologic test (TCT) test, HPV test, and colposcopy at Qilu Hospital of Shandong University from January 2012 to January 2019, after approval of the Qilu Hospital of Shandong University【2018(054)】 . Clinical information of women who met the inclusion criteria was collected retrospectively.

Inclusion criteria: (1) women with normal cytology and hr-HPV infection(s); (2) women accepted colposcopic examination and underwent cervical biopsy under colposcopic guidance.

Exclusion criteria: (1) women with history of treatments to cervical lesions, such as cervical surgery and medicine, et al.; (2) women with incomplete cervical cervix; (3) women with malignant tumors; (4) women with autoimmune diseases or receiving immunotherapy; (5) women with pregnancy; (6) women who had received HPV vaccine.

\section{Cytology test}

Specimen collection, specimen preparations, and results of the tests are performed, according to the instructions of the manufacturers, respectively.

One of those HPV tests could be chosen:

1) Hybrid Capture 2(HC2) High-Risk HPV DNA Test (Qiagen, Gaithersburg, MD, USA): semiquantitative detection of $13 \mathrm{~h}$-HPV types: 16, 18, 31, $33,35,39,45,51,52,56,58,59$ and 68. Samples were considered as positive if the ratio relativelight-unit (RLU)/cut-off(CO) was $>1.0$ (equivalent to $1.0 \mathrm{pg} \mathrm{HPV}$ DNA/mL or $100,000 \mathrm{HPV}$ copies/ $\mathrm{mL}$ ) as described in package insert.

2) the Cobas 4800 System (Roche Diagnostics Corporation, Indianapolis, Indiana): Qualitative detection of HPV 16, HPV 18 and 12 h-HPV (a pool of 12 other hr-HPV types: including HPV $31,33,35,39,45,51,52,56,58,59,66$ and 68).

3) the HPV GenoArray test (Hybribio Biotechnology Ltd. Corp, Chaozhou, Guangdong Province, China): qualitative detection of 15 kinds of hr-HPV types: 16, 18, 31, 33, 35, 39, 45, 51, 52, 53, 56, 58, 59, 66 and 68; 6 kinds of low risk HPV (lr- HPV) types: 6 , $11,42,43,44$ and 81 (CP8304).

\section{HPV test}

Specimen collection, specimen preparations, and results of the tests are performed, according to the instructions of the manufacturers, respectively. ThinPrep (Hologic Inc., Marlborough, Massachusetts, USA)preparations was used, and the cytological diagnosis was performed by experienced cytopathologists, according to the Bethesda system TBS 2001.

\section{Colposcopy and guided cervical biopsies}

All women, enrolled in this study, underwent colposcopy and guided cervical biopsies according to the American Society for Colposcopy and Cervical Pathology Colposcopy Standards recommendations [14]. The histologic diagnosis was regarded as gold standards for this study and was based on the consensus diagnosis of two experienced gynecologic pathologists who were blinded to results of TCT, HPV test, and colposcopic examination. The results of biopsy reports include: normal; low-grade squamous intraepithelial lesion (LSIL) (including CIN 1), high-grade squamous intraepithelial lesion (HSIL) (including CIN 2-3), and cervical cancer. HSIL or worse (HSIL+) includes HSIL and cervical cancer.

\section{Statistical analysis}

Statistical analyses were performed using the SAS 9.4 (SAS Institute, Cary, NC) for windows. The categorical variables were expressed by a percentage (\%). The binary Logistic regression model was used to analyze the detection rate of HSIL+ and cervical cancer in different hrHPV genotype groups. The relationships between the HPV viral load and the detection rate of HSIL+ were analyzed by the Cochran-Armitage Trend test. Results were considered statistically significant at $p$-values $<0.05$.

\section{Result}

Characteristics of the study population

A total of 5880 women with normal cytology and hrHPV infection accepted colposcopic biopsy were enrolled in this study. 4332 women underwent HPV 
genotyping test and 1548 women were hr-HPV DNA positive by $\mathrm{HC} 2 \mathrm{hr}-\mathrm{HPV}$ DNA test (Fig. 1). The median age was 39 years (26-81), and the average age was $39.29 \pm$ 9.72 years. They were divided into 5 age groups.

The prevalence of HPV infection among all age groups showed in Table 1 and Fig. 2. HPV16 and HPV18 were the most common, followed by HPV52 and 58, in all age groups. Among women with normal cytology and HPV infection, 3526(59.97\%) women had normal pathology, 1155(19.64\%) women had LSIL, 1136(19.32\%) had HSIL. The remaining 63(1.07\%) woman was diagnosed with cervical cancer, including 17 women with positive HC2-hr-HPV-DNA-test results, 31 women with single HPV16 infection, 4 women with HPV 18 infection, 8 women with multiple HPV 16 infections without HPV18, 1 woman with HPV 16 and HPV18 infections, and 2 women with HPV58 infection.

\section{Single hr-HPV infection and histopathology in hr-HPV- positive/cytology-negative women}

The detection rates of HSIL+ are different among different hr-HPV types. The rate of HPV16 is highest(34.00\%), followed by HPV31(27.50\%), HPV33(25.58\%), HPV52 (20.77\%), HPV35(17.39\%), HPV58(16.18\%), HPV18(1 2.59\%), HPV51(6.25\%), HPV66(4.88\%), HPV45(4.76\%), HPV39(4.62\%), HPV56(4.69\%), HPV68(4.17\%), HPV59 (3.03\%), HPV53(1.28\%). Compared with single HPV18 infection, the detection rate of HSIL+ was higher in women with single HPV16/31/33/52 infection, with OR values of 3.576(95\% CI:2.442-5.238), 2.633(95\% CI:1.2055.753), 2.386(95\% CI:1.101-5.172), 1.819(95\% CI:1.096-3.02), respectively. There was no significant difference in the detection rates of HSIL+ between single HPV35/39/45/51/56/58/ 59/66/68 and single HPV18 infection. The detection rate of HSIL+ with single HPV53 infection was lower than that in HPV18, while OR value was 0.090 (95\% CI: 0.012-0.670). (Table 2).

\section{Multiple hr-HPV infections and histopathology in hr-HPV- positive/cytology-negative women}

There was no significant difference in the detection rate of HSIL+ between single infection of HPV16 and multiple infections with HPV16 (excluding HPV18) $(P=$ 0.599), not same as HPV18 $(P=0.022)$.

In hr-HPV-positive/cytology-negative women without HPV16/18 infection(s), the HSIL+ detection rates in single hr-HPV infection, double infections and triple or more infections were 12.28, 20.31 and $37.50 \%$, respectively. Compared with the detection rate of HSIL+ in single hr-HPV infection (excluding HPV16/18), OR of the detection rate of HSIL+ in double and triple or more HPV infection was 1.821(95\% CI:1.212-2.738) and 4.287(95\% CI:2.188-8.400), respectively. Moreover, there was a significant difference between double and triple or more HPV infections (excluding HPV16/18) $(P=0.019)$. (Table 3).

\section{Viral load and histopathology in hr-HPV-positive specimen}

One thousand five hundred forty-eight women were hrHPV DNA positive by HC2-hr-HPV DNA test, and they were divided into 3 groups by viral load: low viral load group $(1 \leq \mathrm{RLU} / \mathrm{CO}<10, n=516)$, medium viral load group $(10 \leq \mathrm{RLU} / \mathrm{CO}<100, n=450)$, and high viral load group (RLU/CO $\geq 100, n=582$ ). The HSIL+ detection rates were $5.43,17.33$ and $27.15 \%$ in 3 groups, respectively; with the increase of viral load, the higher the risk was $\left(x^{2}=91.01, P<0.0001\right)$. The detection rates of invasive cancer in 3 groups were $0.19,1.33$ and $1.72 \%$, respectively. As the same, viral load is proportional to the $\operatorname{risk}\left(\chi^{2}=5.757, P=0.016\right)$. (Table 4$)$.

\section{Age and histopathology in hr-HPV-positive/cytology- negative women}

HSIL+ detection rate changed by different age groups. In age $<30,31-40,41-50,51-60,>60$ group, HSIL+ detection rate were $24.80 \% 、 22.10 \% 、 19.59 \% 、 14.29$, and $12.61 \%$, respectively. The cancer detection rate was the highest in the age 54-60 group, which was $2.75 \%$. However, the detection rate of cancer in age $<30$ group (0.50\%) was lowest (Table 5, Fig.3).

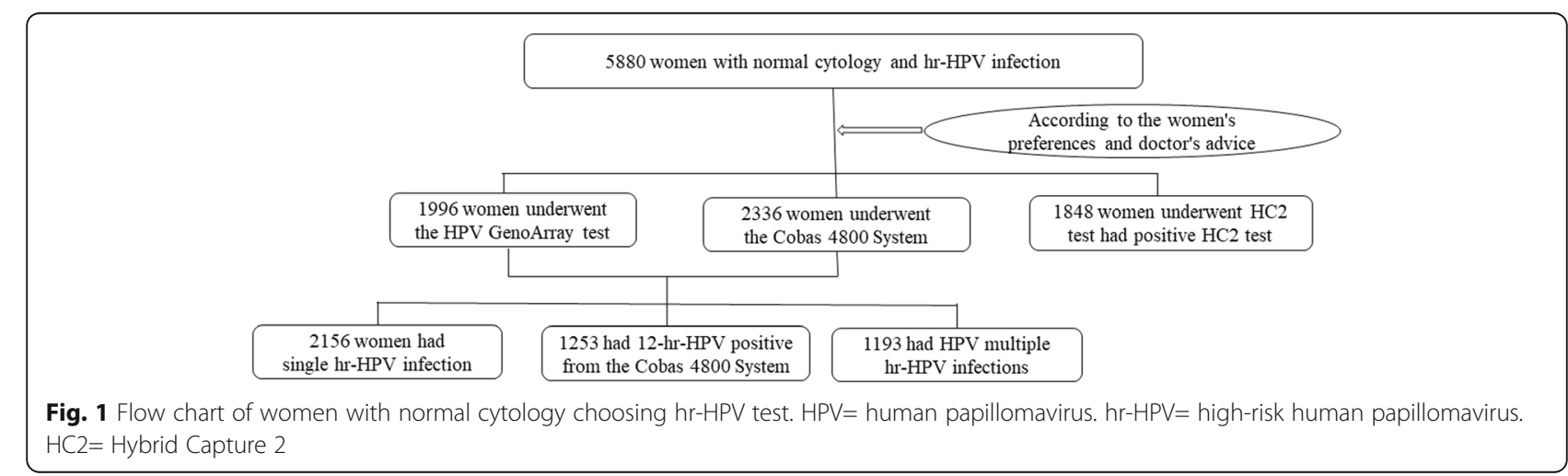


Table 1 Distribution of age and hr-HPV genotypes in hr-HPV-positive/cytology-negative women

\begin{tabular}{|c|c|c|c|c|c|c|c|c|c|c|c|c|c|c|c|c|c|c|}
\hline \multirow[t]{2}{*}{ Age } & \multicolumn{17}{|c|}{ hr-HPV genotypes } & \multirow[t]{2}{*}{ N } \\
\hline & $\overline{16}$ & 18 & 31 & 33 & 35 & 39 & 45 & 51 & 52 & 53 & 56 & 58 & 59 & 66 & 68 & $12-h r^{a}$ & $\overline{\mathrm{HC} 2^{\mathrm{b}}}$ & \\
\hline$<30$ & 332 & 92 & 16 & 15 & 11 & 27 & 5 & 29 & 59 & 21 & 26 & 46 & 15 & 24 & 14 & 286 & 223 & 992 \\
\hline $30-39$ & 595 & 156 & 26 & 38 & 22 & 45 & 15 & 54 & 118 & 59 & 53 & 92 & 30 & 25 & 34 & 578 & 575 & 2140 \\
\hline $40-49$ & 490 & 165 & 31 & 33 & 17 & 37 & 13 & 39 & 101 & 41 & 47 & 73 & 24 & 29 & 32 & 509 & 496 & 1868 \\
\hline $50-59$ & 50 & 16 & 2 & 1 & 3 & 3 & 4 & 5 & 13 & 7 & 3 & 12 & 1 & 1 & 3 & 58 & 47 & 182 \\
\hline$\geq 60$ & 152 & 40 & 8 & 13 & 7 & 11 & 1 & 14 & 46 & 25 & 15 & 35 & 12 & 16 & 12 & 195 & 207 & 698 \\
\hline $\mathbf{N}^{c}$ & 1619 & 469 & 83 & 100 & 60 & 123 & 38 & 141 & 337 & 153 & 144 & 258 & 82 & 95 & 95 & 1626 & 1548 & 588 \\
\hline
\end{tabular}

HPV human papillomavirus

hr-HPV high-risk human papillomavirus

$\mathrm{a}=12 \mathrm{hr}$-HPV (a pool of 12 other hr-HPV types: including HPV 31,33,35,39,45,51,52,56,58,59,66 and 68) from the Cobas 4800 System

$\mathrm{b}=13 \mathrm{hr}-\operatorname{HPV}(16,18,31,33,35,39,45,51,52,56,58,59$ and 68) by Hybrid Capture 2(HC2)High-Risk HPV DNA Test

${ }^{c}=$ The sum of women with the type-specific hr-HPV infection(s) and it would be counted multiple times if the person has multiple hr-HPV infections

\section{Discussion}

Tests designed to stratify risks, such as HPV tests and cytological tests, play a vital role in managing patients. Most of the HPV-negative women is associated with a very low risk for developing cervical cancer [4-7]. One of the clinicians' work is to identify women at high risk of cervical lesions from HPV-positive and cytologynegative women.

This study chose HSIL+ as the primary endpoint, because the purpose of cervical cancer screening is to detect easily treatable precancerous lesions, most commonly defined as CIN2 and greater. And choosing CIN3 + as the endpoint would miss some invasive cancers which developed from a part of CIN2, although it will increase the rate of referral of colposcopy. However, the primary endpoint of HSIL + is not ideal enough. One of the reasons is that CIN2 is an equivocal diagnosis of precancer, part of CIN2 can regress spontaneously, and the rest may develop to CIN3 or even invasive cancer [15].

The guidelines recommend that women with normal cytology should undergo a colposcopy examination immediately if they have HPV16/18 infection, rather than return testing at 1 year [10]. However, a 5-year study showed that non-HPV 16/18-positive women with the normal cytological result also had an $11.4 \%$ risk of HSIL [16]. Another study also found that some of the 12 nonHPV16/18 genotypes had the same risk for developing to HSIL as HPV16/18 [17]. And this study investigated the difference in the detection rate of HSIL+ in different genotypes in women with normal cytology by Binary

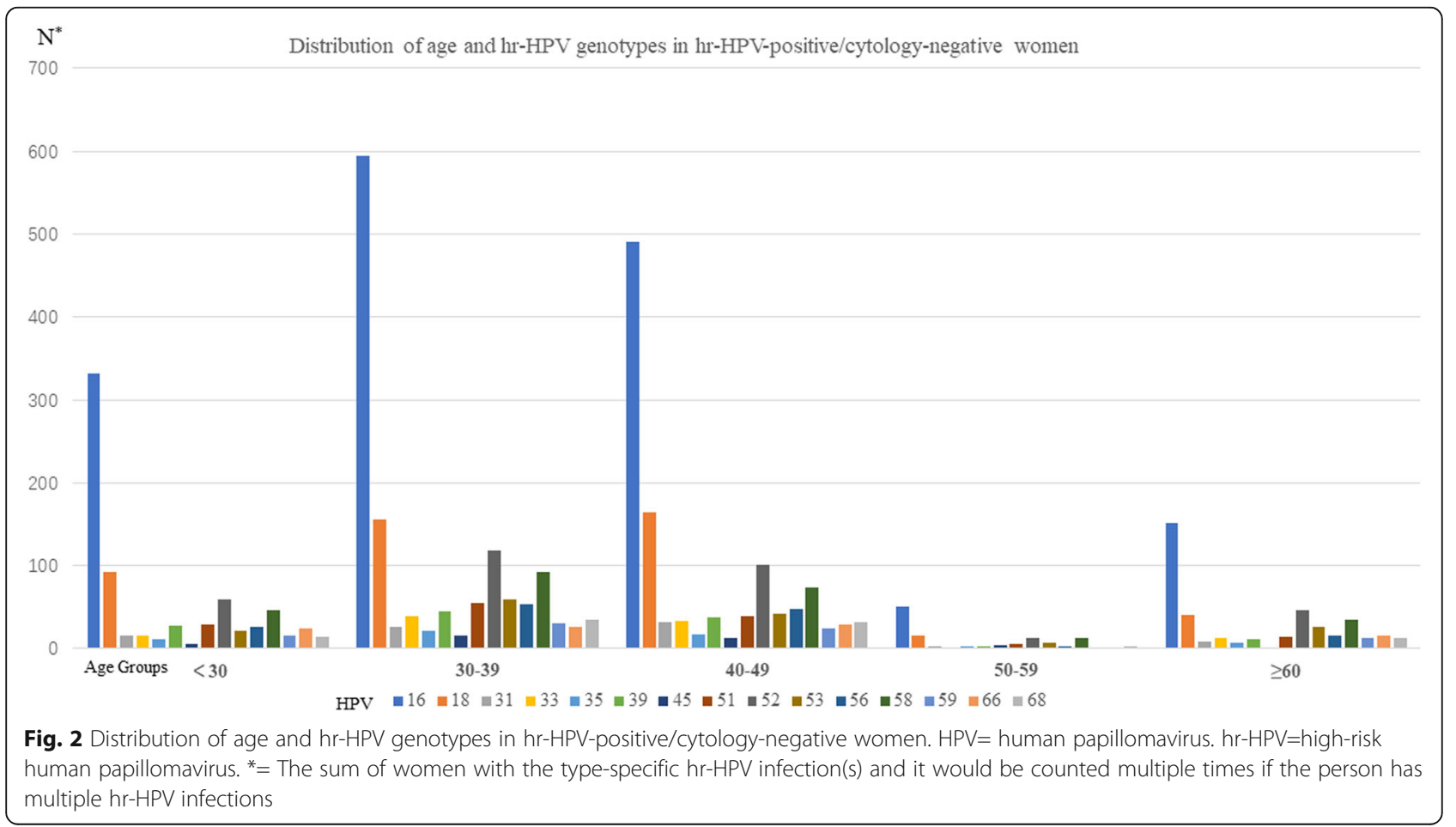


Table 2 Distribution of hr-HPV genotype and histological results among single-hr-HPV-positive/cytology-negative women

\begin{tabular}{|c|c|c|c|c|c|c|c|}
\hline \multirow{2}{*}{$\begin{array}{l}\text { HPV } \\
\text { Types }\end{array}$} & \multicolumn{7}{|c|}{ Histological Results } \\
\hline & TOTAL & $\operatorname{NORMAL}(n, \%)$ & LSIL(n,\%) & HSIL $(n, \%)$ & $C A(n, \%)$ & $\mathrm{HSIL}+(\mathrm{n}, \%)$ & $\mathrm{HSIL}+\mathrm{OR}(95 \% \mathrm{Cl})$ \\
\hline 16 & 1047 & $522(49.86)$ & $169(16.14)$ & $325(31.04)$ & $31(2.96)$ & $356(34.00)$ & $3.576(2.442-5.238)$ \\
\hline 18 & 270 & $175(64.81)$ & $61(22.59)$ & $30(11.11)$ & $4(1.48)$ & $34(12.59)$ & 1 \\
\hline 31 & 40 & $19(47.50)$ & $10(25.00)$ & $11(27.50)$ & $0(0.00)$ & $11(27.50)$ & $2.633(1.205-5.753)$ \\
\hline 33 & 43 & $24(55.81)$ & $8(18.60)$ & $11(25.58)$ & $0(0.00)$ & $11(25.58)$ & $2.386(1.101-5.172)$ \\
\hline 35 & 23 & $14(60.87)$ & $5(21.74)$ & $4(17.39)$ & $0(0.00)$ & $4(17.39)$ & $1.461(0.469-4.554)$ \\
\hline 39 & 65 & $49(75.38)$ & $13(20.00)$ & $3(4.62)$ & $0(0.00)$ & $3(4.62)$ & $0.336(0.100-1.130)$ \\
\hline 45 & 21 & $16(76.19)$ & $4(19.05)$ & $1(4.76)$ & $0(0.00)$ & $1(4.76)$ & $0.347(0.045-2.670)$ \\
\hline 51 & 64 & $44(68.75)$ & $16(25.00)$ & $4(6.25)$ & $0(0.00)$ & $4(6.25)$ & $0.463(0.158-1.355)$ \\
\hline 52 & 183 & $115(62.84)$ & $30(16.39)$ & $38(20.77)$ & $0(0.00)$ & $38(20.77)$ & $1.819(1.096-3.020)$ \\
\hline 53 & 78 & $62(79.49)$ & $15(19.23)$ & $1(1.28)$ & $0(0.00)$ & $1(1.28)$ & $0.090(0.012-0.670)$ \\
\hline 56 & 64 & $41(64.06)$ & $20(31.25)$ & $3(4.69)$ & $0(0.00)$ & $3(4.69)$ & $0.341(0.101-1.149)$ \\
\hline 58 & 136 & $86(63.24)$ & $28(20.59)$ & $20(14.71)$ & $2(1.47)$ & $22(16.18)$ & $1.340(0.749-2.395)$ \\
\hline 59 & 33 & $22(66.67)$ & $10(30.30)$ & $1(3.03)$ & $0(0.00)$ & $1(3.03)$ & $0.217(0.029-1.639)$ \\
\hline 66 & 41 & $29(70.73)$ & $10(24.39)$ & $2(4.88)$ & $0(0.00)$ & $2(4.88)$ & $0.356(0.082-1.542)$ \\
\hline 68 & 48 & $37(77.08)$ & 9 (18.75) & $2(4.17)$ & $0(0.00)$ & $2(4.17)$ & $0.302(0.070-1.300)$ \\
\hline $\mathbf{N}^{a}$ & 2156 & $1255(58.21)$ & $408(18.920$ & $456(21.15)$ & $37(1.72)$ & $493(22.87)$ & - \\
\hline
\end{tabular}

HPV human papillomavirus

hr-HPV high-risk human papillomavirus

LSIL low-grade squamous intraepithelial lesion

HSIL high-grade squamous intraepithelial lesion

CA cervical cancer

$H S I L+$ high-grade squamous intraepithelial lesion or worse

$O R$ odds ratio

$\mathrm{Cl}$ confidence interval

${ }^{\mathrm{a}}=$ The total number of women with hr-HPV positive in the corresponding histological results groups

Logistic Regression Model, based on the HSIL+ detection rate of HPV18.

HPV16 is the most common carcinogenic genotype, even 2-3 times more than other HPV genotypes [11, 12]. This study found that the risk of HSIL+ in HPV16 positive women was higher than that of HPV18(OR:3.576, 95\% CI: 2.442-5.238), and the high carcinogenicity of HPV16 was verified again. HPV31, HPV33, and HPV52 showed a higher detection rate of HSIL+ than HPV18. A 12-year follow-up study in Denmark showed that the absolute risk of CIN3+ in patients with HPV31 positive was 14.3\% (CI: 9.1-19.4) [18]. Previous studies showed HPV33 was a relative of HPV16 [19], and HPV33 infection was associated with high absolute risks for progression to high-grade cervical lesions [20-22].

This study found that HPV 52 and HPV58 were the most common type of HPV infection apart from HPV16/18, which was same with previous studies showed HPV 52 and HPV58 were common in Asia, including Korea [23-25] and China [26-28]. Recently, high carcinogenicity of HPV58 and HPV45 has attracted much clinicians' attention. A meta-analysis showed that the pattern for HPV58 in Eastern Asia was different than elsewhere, and HPV58 continues to rise in the proportion of cervical diseases at all levels, accounting for $10.2 \% \pm 3.9 \%$ of all invasive cervical cancer with HPV infection [29]. Another study showed that HPV-58 is more prominent in HSIL and invasive cervical cancer patients in Japan [30]. In this study, in women with single hr-HPV infection, excluding HPV16/18, cervical cancer only occurred in 2 women infected with HPV58, consistent with previous studies in southwestern China that HPV58 is common in ICC [31]. HPV45 is a close relative of HPV18 [19, 32], and some studies reported that HPV45 was the third most common genotype involved in invasive cervical carcinoma, found in $6 \%$ of cervical cancers [33]. However, this study did not observe the high carcinogenicity of HPV45 in women with hr-HPV infection and normal cytology, which was related to the abnormality of cytology in women infected with HPV45. And a study reported that only $0.5 \%$ of women with HPV 45 infection had normal cytology [34].

Multivariate analysis showed that the risk of cervical cancer was 19.9 times higher in women with single HPV infection, and 31.8 times higher in those with multiple HPV infection [35]. This suggests that multiple infections have a cumulative effect on developing to HSIL+. This study analyzed the association between the detection rate of HSIL+ and multiple hr-HPV infections, 
Table 3 Distribution of hr-HPV genotypes and histological results among hr-HPV-positive/cytology-negative women

\begin{tabular}{|c|c|c|c|c|c|c|c|}
\hline \multirow[t]{2}{*}{ HPV Type(s) } & \multicolumn{7}{|c|}{ Histological Results } \\
\hline & TOTAL & $\operatorname{NORMAL}(n, \%)$ & LSIL(n,\%) & HSIL(n,\%) & $C A(n, \%)$ & $\mathrm{HSIL+(n, \% )}$ & $\mathrm{HSIL}+\mathrm{OR}(95 \% \mathrm{Cl})$ \\
\hline \multicolumn{8}{|c|}{ HPV infection(s) with 16 and/or 18} \\
\hline HPV16 & 1047 & $522(49.86)$ & $169(16.14)$ & $325(31.04)$ & $31(2.96)$ & $356(34.00)$ & \\
\hline HPV18 & 270 & $175(64.81)$ & $61(22.59)$ & $30(11.11)$ & $4(1.48)$ & $34(12.59)$ & \\
\hline $16+$ other $(s)^{a}$ & 492 & $213(43.29)$ & $105(21.34)$ & $166(33.74)$ & $8(1.63)$ & $174(35.37)$ & \\
\hline $18+$ other $(s)^{a}$ & 120 & $56(46.67)$ & $38(31.67)$ & $26(21.67)$ & $0(0.00)$ & $26(21.67)$ & \\
\hline $16+18+$ other(s) ${ }^{\text {a }}$ & 79 & $30(37.97)$ & $17(21.52)$ & $31(39.24)$ & $1(1.27)$ & $32(40.51)$ & \\
\hline \multicolumn{8}{|c|}{ No. of hr HPV type(s) without HPV16 or 18} \\
\hline 1 type & 839 & $558(66.51)$ & $178(21.22)$ & $101(12.04)$ & $2(0.24)$ & 103 (12.28) & 1 \\
\hline 2 types $^{c}$ & 192 & $118(61.46)$ & $35(18.23)$ & $39(20.31)$ & $0(0.00)$ & $39(20.31)$ & $1.821(1.212-2.738)$ \\
\hline$\geq 3$ types $^{d}$ & 40 & $19(47.50)$ & $6(15.00)$ & $15(37.50)$ & $0(0.00)$ & $15(37.50)$ & $4.287(2.188-8.400)$ \\
\hline \multicolumn{8}{|l|}{ Unknown type(s) } \\
\hline $\mathrm{HC}^{\mathrm{e}}$ & 1548 & $984(63.57)$ & $300(19.38)$ & $247(15.96)$ & $17(1.10)$ & $264(17.05)$ & \\
\hline $12 \mathrm{hr}-\mathrm{HPV}^{\mathrm{f}}$ & 1253 & $851(67.92)$ & $246(19.63)$ & $156(12.45)$ & $0(0.00)$ & $156(12.45)$ & \\
\hline \multicolumn{8}{|l|}{ Total } \\
\hline $\mathrm{N}^{\mathrm{g}}$ & 5880 & $3526(59.97)$ & $1155(19.64)$ & $1136(19.32)$ & $63(1.07)$ & 1199 (20.39) & \\
\hline
\end{tabular}

HPV human papillomavirus

hr-HPV high-risk human papillomavirus

LSIL low-grade squamous intraepithelial lesion

$H S I L$ high-grade squamous intraepithelial lesion

CA cervical cancer

$H S I L+$ high-grade squamous intraepithelial lesion or worse

$O R$ odds ratio

$\mathrm{Cl}$ confidence interval

${ }^{a}=$ hr-HPV genotypes except HPV16 or 18

$\mathrm{b}=$ single hr-HPV infection without HPV16 or 18

$\mathrm{c}^{\mathrm{s}}$ double hr-HPV infections HPV16 or 18

$\mathrm{d}=$ triple or more hr-HPV infections HPV 16 or 18

$\mathrm{e}=$ infection(s) with a pool of 12 other hr-HPV types (including HPV 31,33,35,39,45,51,52,56,58,59,66 and 68) that did not know the specific type of HPV (from

Cobas 4800 HPV test)

$\mathrm{f}=13 \mathrm{hr}$-HPV types $(16,18,31,33,35,39,45,51,52,56,58,59$ and 68) tested by Hybrid Capture 2(HC2)High-Risk HPV DNA Test

${ }^{\mathrm{g}}=$ The total number of people with hr-HPV positive in the corresponding histological results groups

excluding HPV16/18. Compared with single hr-HPV infection, the detection rate of HSIL+ in double hr-HPV infections (OR: 1.821, 95\% CI:1.212-2.738) and $\geq$ triple hr-HPV infections (OR:4.287, 95\% CI:2.188-8.400) increased significantly, and there was a significant difference in the detection rate of HSIL + between double hr-
HPV infection and $\geq$ triple hr-HPV infection $(P=0.019)$, which means that more hr-HPV genotypes infected in women, the higher the HSIL detection rate.

It is controversial whether the viral hr-DNA load can be used as a reliable marker to predict cervical lesions. Previous studies have reported that HPV viral load has

Table 4 Histological results and viral load among hr-HPV-positive/cytology-negative women

\begin{tabular}{|c|c|c|c|c|c|c|}
\hline \multirow[t]{2}{*}{ Viral Load } & \multicolumn{6}{|c|}{ Histological Results } \\
\hline & TOTAL & NORMAL $(n, \%)$ & LSIL $(n, \%)$ & HSIL (n,\%) & CA $(n, \%)$ & $\mathrm{HSIL}+(\mathrm{n}, \%)$ \\
\hline $1 \leq \mathrm{RLU} / \mathrm{CO}<10$ & 516 & 409 (79.26) & $79(15.31)$ & $27(5.23)$ & $1(0.19)$ & $28(5.43)$ \\
\hline $10 \leq \mathrm{RLU} / \mathrm{CO}<100$ & 450 & $281(62.44)$ & $91(20.22)$ & $72(16.00)$ & $6(1.33)$ & $78(17.33)$ \\
\hline $\mathrm{RLU} / \mathrm{CO} \geq 100$ & 582 & $294(50.52)$ & $130(22.34)$ & $148(25.43)$ & $10(1.72)$ & $158(27.15)$ \\
\hline$N^{a}$ & 1548 & 984 (63.57) & $300(19.38)$ & $247(15.96)$ & $17(1.10)$ & $264(17.05)$ \\
\hline
\end{tabular}

HPV human papillomavirus

$h r-H P V$ high-risk human papillomavirus

$R L U / C O$ the ratio relative-light-units /cut-off

LSIL low-grade squamous intraepithelial lesion

$H S I L$ high-grade squamous intraepithelial lesion

CA cervical cancer

$H S I L+$ high-grade squamous intraepithelial lesion and cervical cancer

${ }^{a}=$ The total number of people with different RLU in the corresponding histological results groups 
Table 5 Age and histological results among hr-HPV-positive/cytology-negative women

\begin{tabular}{|c|c|c|c|c|c|c|}
\hline \multirow[t]{2}{*}{ AGE } & \multicolumn{6}{|c|}{ Histological Results } \\
\hline & $\overline{T O T A L}$ & $\operatorname{NORMAL}(\mathrm{n}, \%)$ & LSIL(n,\%) & $\mathrm{HSIL}(\mathrm{n}, \%)$ & $\mathrm{CA}(\mathrm{n}, \%)$ & $\mathrm{HSIL}+(\mathrm{n}, \%)$ \\
\hline$<30$ & 992 & $565(56.96)$ & $181(18.25)$ & $241(24.29)$ & $5(0.50)$ & $246(24.80)$ \\
\hline $31-40$ & 2140 & $1249(58.36)$ & $418(19.53)$ & $453(21.17)$ & $20(0.93)$ & $473(22.10)$ \\
\hline $41-50$ & 1868 & $1117(59.80)$ & $385(20.61)$ & $341(18.25)$ & $25(1.34)$ & $336(19.59)$ \\
\hline $51-60$ & 182 & $120(65.93)$ & 36 (19.78) & $21(11.54)$ & $5(2.75)$ & $26(14.29)$ \\
\hline$>60$ & 698 & $475(68.05)$ & 135 (19.34) & $80(11.46)$ & $8(1.15)$ & $88(12.61)$ \\
\hline $\mathrm{N}^{\mathrm{a}}$ & 5880 & $3526(59.97)$ & $1155(19.64)$ & $1136(19.32)$ & $63(1.07)$ & $1199(20.39$ \\
\hline
\end{tabular}

HPV human papillomavirus

hr-HPV high-risk human papillomavirus

LSIL low-grade squamous intraepithelial lesion

$H S I L$ high-grade squamous intraepithelial lesion

CA cervical cancer

$H S I L+$ high-grade squamous intraepithelial lesion and cervical cancer

${ }^{a}=$ The total number of people with different ages in the corresponding histological results groups

been associated with persistence of HPV infection and subsequent cervical precancerous lesions [13, 36, 37]. However, a research showed that the high viral load of $13 \mathrm{~h}$-HPV types could not predict HSIL+ [38]. There were little previous researches to analyze the correlation between the severity of cervical lesions and viral DNA load in women with normal smears. A study reported that the level of viral load not predictive of HPV persistence or the development of cervical intraepithelial neoplasia and only HPV16 infection was significantly more likely to persist and to develop CIN in women under 30 with normal cytology $[39,40]$. This study found that the higher viral load, the higher the detection rate of HSIL+ in women with normal cytology $\left(x^{2}=91.01, P<0.0001\right)$,

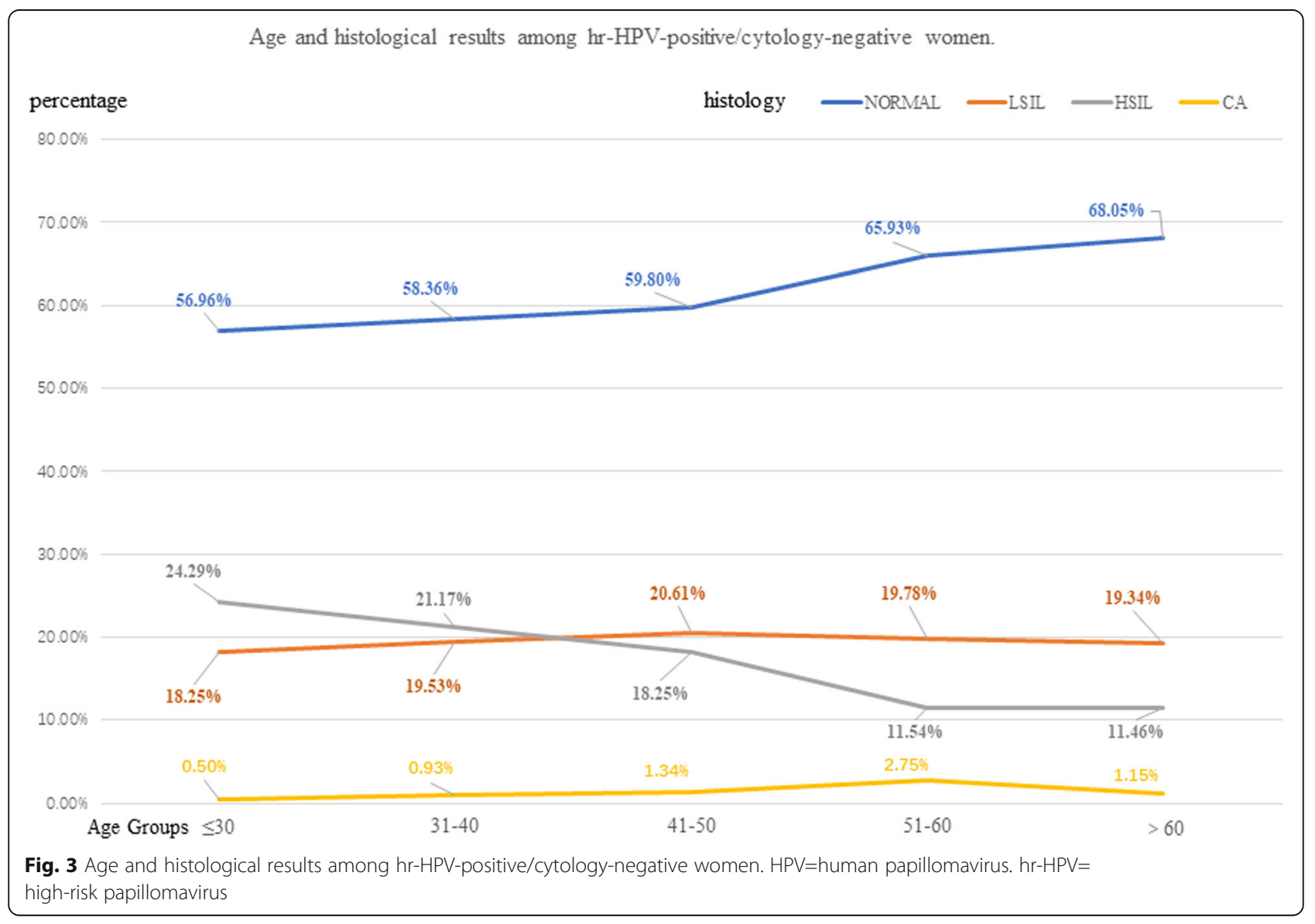


same as the detection rate of cervical cancer $(x 2=5.757$, $P=0.016$ ), which may be correlated to the fact that patients with low-load HPV infection are more likely to be eliminated, while those with high-load HPV infection are more difficult to eliminate [41].

This study found that the absolute value of HSIL+ detection rate decreased with age, while the absolute value of cancer detection rate increased with age, in women with normal cytology and hr-HPV infection. The time of hr-HPV infection is short, and cervical cell morphology has not changed in young women, what's more, the proportion of CIN2 that can regress is higher in young women [14]. However, hr-HPV infection time is longer, and the proportion of CIN2 that progresses to CIN3 or invasive cancer is higher, while the percentage of CIN2 that can regress is smaller, in older women [14, 40]. Therefore, older women had lower HSIL+ detection rate and higher cervical cancer detection rate in women with normal cytology and HPV infection.

\section{Conclusion}

In conclusion, about one in five hr-HPV-positive/cytologynegative women are diagnosed with HSIL+. Women with HPV 16/18/31/33/52/58 infections, multiple HPV infections whether combined with HPV16/18 infections, as well as high viral load, have a higher detection rate of HSIL+, although they have normal cytology.

\section{Limitation}

This study was a cross-sectional study without follow-up and it could not estimate the cumulative risk of cervical lesions within a period. The population enrolled in this study is the patients who underwent colposcopy in Qilu Hospital, Shandong University. So, the results of this study can not be directly applied to the general screening population, but it has certain reference significance for the diagnosis and treatment of patients coming to the hospital. Besides, we can not ignore the heterogeneity of 3 HPV assays and specifically analyze women infected with $12 \mathrm{~h}-\mathrm{HPV}$.

\section{Acknowledgements}

Not applicable.

\section{Authors' contributions}

ZW designed the study and completed the initial draft of paper. TL, YW and YG conducted the data collection. HW and JL carried out the analysis of the data. XY and BC founded for the study. All authors read and approved the final manuscript.

\section{Funding}

National Natural Science Foundation of China and Science, Grant/Award Number: 81874105;

National Clinical Research Center for Gynecological Oncology, Grant/Award Number:2015BAI13B05;

National Natural Science Foundation of China and Science, Grant/Award Number: 81372809;
National Key Research \& Development Program of China, Grant/Award Number: 2016YFC1302903.

The funding sources acknowledged the design of the study but did not influence the process of our study, including data collection, analysis, and interpretation and the reporting of results.

\section{Availability of data and materials}

We declared that materials described in the manuscript, including all relevant raw data, will be freely available to any scientist wishing to use them for non-commercial purposes, without breaching participant confidentiality. You can contact the corresponding author through the email to get the data.

Ethics approval and consent to participate

All procedures in studies involving human participants were performed in accordance with ethical standards and approved by the Ethics Committee of Shandong University [2018 (054)].

\section{Consent for publication}

The manuscript was approved for publication by all authors.

\section{Competing interests}

The authors declare that they have no competing interests.

\section{Author details}

1Department of Gynecology, Qilu Hospital of Shandong University, Jinan, China. ${ }^{2}$ West China School of Medicine, Sichuan University, Chengdu, China.

Received: 24 September 2019 Accepted: 1 January 2020

Published online: 21 May 2020

\section{References}

1. Walboomers JM, Jacobs MV, Manos MM, Bosch FX, Kummer JA, Shah KV, et al. Human papillomavirus is a necessary cause of invasive cervical cancer worldwide. J Pathol. 1999;189(1):12-9.

2. Bulkmans NW, Berkhof J, Rozendaal L, van Kemenade FJ, Boeke AJ, Bulk S, et al. Human papillomavirus DNA testing for the detection of cervical intraepithelial neoplasia grade 3 and cancer: 5 -year follow-up of a randomised controlled implementation trial. Lancet. 2007;370:1764-72.

3. Sankaranarayanan R, Nene BM, Shastri SS, Jayant K, Muwonge R, Budukh AM, et al. HPV screening for cervical cancer in rural India. N Engl J Med. 2009;360(14):1385-94.

4. Ronco G, Giorgi-Rossi P, Carozzi F, Confortini M, Dalla Palma P, Del Mistro A, et al. New Technologies for Cervical Cancer Screening (NTCC) working group. Efficacy of human papillomavirus testing for the detection of invasive cervical cancers and cervical intraepithelial neoplasia: a randomised controlled trial. Lancet Oncol. 2010;11(3):249-57.

5. Ogilvie GS, van Niekerk D, Krajden M, Smith LW, Cook D, Gondara L, et al. Effect of screening with primary cervical HPV testing vs cytology testing on high- grade cervical intraepithelial neoplasia at 48 months: the HPV FOCAL randomized clinical trial. JAMA. 2018;320(1):43-52.

6. Ronco G, Dillner J, Elfström KM, Tunesi S, Snijders PJ, Arbyn M, et al. Efficacy of HPV-based screening for prevention of invasive cervical cancer: follow-up of four European randomised controlled trials. Lancet. 2014;383(9916):524-32.

7. Dillner J, Rebolj M, Birembaut P, Petry KU, Szarewski A, Munk C, et al. Longterm predictive values of cytology and human papillomavirus testing in cervical cancer screening: joint European cohort study. BMJ. 2008;337:a1754.

8. Wentzensen N, Arbyn M, Berkhof J, Bower M, Canfell K, Einstein M, et al. Eurogin 2016 roadmap: how HPV knowledge is changing screening practice. Int J Cancer. 2017;140(10):2192-200.

9. lacobellis M, Violante C, Notarachille G, Simone A, Scarfi R, Giuffre G. Clinical validation of REALQUALITY RQ-HPV screen according to the international guidelines for human papillomavirus DNA test requirements for cervical screening. Virol J. 2018;15(1):48.

10. COMMITTEE ON PRACTICE. B-G. practice bulletin no. 168: cervical Cancer screening and prevention [J]. Obstet Gynecol. 2016;128(4):e111-30.

11. Preventive Services Task Force US, Curry SJ, Krist AH, Owens DK, Barry MJ, Caughey AB, et al. Screening for cervical cancer: U.S. Preventive Services Task Force recommendation statement. JAMA. 2018;320(7):674-86. 
12. Huh WK, Ault KA, Chelmow D, Davey DD, Goulart RA, Garcia FA, et al. Use of primary high-risk human papillomavirus testing for cervical cancer screening: interim clinical guidance. Gynecol Oncol. 2015;136(2):178-82.

13. Lorincz AT, Castle PE, Sherman ME, Scott DR, Glass AG, Wacholder S, et al. Viral load of human papillomavirus and risk of CIN3 or cervical cancer. Lancet. 2002;360(9328):228-9.

14. Khan MJ, Werner CL, Darragh TM, Guido RS, Mathews C, Moscicki AB, et al American Society for Colposcopy and Cervical Pathology Colposcopy Standards Colposcopy Standards: role of colposcopy, benefits, potential harms, and terminology for colposcopic practice. J Low Genit Tract Dis. 2017;21(4):223-9.

15. Steenbergen RD, Snijders PJ, Heideman DA, Meijer CJ. Clinical implications of (epi)genetic changes in HPV-induced cervical precancerous lesions. Nat Rev Cancer. 2014;14(6):395-405

16. Uijterwaal MH, Polman NJ, Van Kemenade FJ, Van Den Haselkamp S, Witte Bl, Rijkaart D, et al. Five-year cervical (pre)cancer risk of women screened by HPV and cytology testing. Cancer Prev Res (Phila). 2015;8(6):502-8.

17. Sung YE, Ki EY, Lee YS, Hur SY, Lee A, Park JS. Can human papillomavirus (HPV) genotyping classify non-16/18 high-risk HPV infection by riskstratification? J Gynecol Oncol. 2016;27:e56.

18. Kjær SK, Frederiksen K, Munk C, Iftner T. Long-term absolute risk of cervica intraepithelial neoplasia grade 3 or worse following human papillomavirus infection: role of persistence. J Natl Cancer Inst. 2010;102(19):1478-88.

19. Gottschling M, Göker M, Stamatakis A, Bininda-Emonds OR, Nindl I, Bravo IG. Quantifying the phylodynamic forces driving papillomavirus evolution. Mol Biol Evol. 2011;28(7):2101-13.

20. Schiffman M, Hyun N, Raine-Bennett TR, Katki H, Fetterman B, Gage JC, et al. A cohort study of cervical screening using partial HPV typing and cytology triage. Int J Cancer. 2016;139(11):2606-15.

21. Cuzick J, Ho L, Terry G, Kleeman M, Giddings M, Austin J, et al. Individual detection of 14 high risk human papilloma virus genotypes by the PapType test for the prediction of high grade cervical lesions. J Clin Virol. 2014;60(1):44-9.

22. Schiffman M, Burk RD, Boyle S, Raine-Bennett T, Katki HA, Gage JC, et al. A study of genotyping for Management of Human Papillomavirus-Positive, cytology-negative cervical screening results. J Clin Microbiol. 2015;53(1):52-9.

23. So KA, Kim MJ, Lee KH, Lee $I H$, Kim MK, Lee $Y K$, et al. The impact of high-risk HPV genotypes other than HPV 16/18 on the natural course of abnormal cervical cytology: a Korean HPV cohort study. Cancer Res Treat. 2016 Oct; 48(4):1313-20.

24. So KA, Hong JH, Lee JK. Human papillomavirus prevalence and type distribution among 968 women in South Korea. J Cancer Prev. 2016;21(2): 104-9.

25. Nah EH, Cho S, Kim S, Cho HI. Human papillomavirus genotype distribution among 18,815 women in 13 Korean cities and relationship with cervical cytology findings. Ann Lab Med. 2017;37(5):426-33.

26. Chen HC, Schiffman M, Lin CY, Pan MH, You SL, Chuang LC, et al. Persistence of type-specific human papillomavirus infection and increased long-term risk of cervical cancer. J Natl Cancer Inst. 2011;103(18):1387-96.

27. Jing L, Zhong X, Huang W, Liu Y, Wang M, Miao Z, et al. HPV genotypes and associated cervical cytological abnormalities in women from the Pearl River Delta region of Guangdong province, China: a cross-sectional study. BMC Infect Dis. 2014;14:388.

28. Zhang L, Bi Q, Deng H, Xu J, Chen J, Zhang M, et al. Human papillomavirus infections among women with cervical lesions and cervical cancer in eastern China: genotype-specific prevalence and attribution. BMC Infect Dis. 2017;17(1):107.

29. Guan P, Howell-Jones R, Li N, Bruni L, de Sanjosé S, Franceschi S, et al. Human papillomavirus types in 115,789 HPV-positive women: a metaanalysis from cervical infection to cancer. Int J Cancer. 2012;131(10): 2349-59.

30. Asato T, Maehama T, Nagai Y, Kanazawa K, Uezato H, Kariya K. A large casecontrol study of cervical Cancer risk associated with human papillomavirus infection in Japan, by nucleotide sequencing-based genotyping. J Infect Dis. 2004;189(10):1829-32.

31. Tang Y, Zheng L, Yang S, Li B, Su H, Zhang LP. Epidemiology and genotype distribution of human papillomavirus (HPV) in Southwest China: a crosssectional five years study in non-vaccinated women. Virol J. 2017;14(1):84.

32. Bernard HU, Burk RD, Chen Z, van Doorslaer K, Zur Hausen H, de Villiers EM. Classification of papillomaviruses (PVs) based on 189 PV types and proposal of taxonomic amendments. Virology. 2010;401(1):70-9.
33. de Sanjose S, Quint WG, Alemany L, Geraets DT, Klaustermeier JE, Lloveras B, et al. Human papillomavirus genotype attribution in invasive cervical cancer: a retrospective cross-sectional worldwide study. Lancet Oncol. 2010;11(11): 1048-56.

34. Bruni L, Diaz M, Castellsagué X, Ferrer E, Bosch FX, de Sanjosé S. Cervical human papillomavirus prevalence in 5 continents: meta-analysis of 1 million women with normal cytological findings. J Infect Dis. 2010;202(12):1789-99.

35. Lee SA, Kang D, Seo SS, Jeong JK, Yoo KY, Jeon YT, et al. Multiple HPV infection in cervical cancer screened by HPVDNAChip. Cancer Lett. 2003; 198(2):187-92.

36. Lai CH, Chao A, Chang CJ, Chao FY, Huang HJ, Hsueh S, et al. Host and viral factors in relation to clearance of human papillomavirus infection: a cohort study in Taiwan. Int J Cancer. 2008;123(7):1685-92.

37. Bae J, Seo SS, Park YS, Dong SM, Kang S, Myung SK, et al. Natural history of persistent high-risk human papillomavirus infections in Korean women. Gynecol Oncol. 2009;115(1):75-80.

38. Muñoz N, Hernandez-Suarez G, Méndez F, Molano M, Posso H, Moreno V, Murillo R, Ronderos M, Meijer C, Muñoz Á. Persistence of HPV infection and risk of high-grade cervical intraepithelial neoplasia in a cohort of Colombian women. Br J Cancer 2009;100(7):1184-90.

39. Mills AM, Paquette C, Castle PE, Stoler MH. Risk stratification by p16 Immunostaining of CIN1 biopsies a retrospective study of patients from the Quadrivalent HPV vaccine trials. Am J Surg Pathol. 2015;39(5):611-7.

40. Carcopino X, Bolger N, Henry M, Mancini J, Boubli L, Olive D, et al. Evaluation of type-specific HPV persistence and high-risk HPV viral load quantitation in HPV positive women under 30 with normal cervical cytology. J Med Virol. 2011;83(4):637-43.

41. Mariëlle AE Nobbenhuis, Theo JM Helmerhorst, Adriaan JC van den Brule, Lawrence Rozendaal, Feja J Voorhorst, P Dick Bezemer, René HM Verheijen, Chris JLM Meijer, Cytological regression and clearance of high-risk human papillomavirus in women with an abnormal cervical smear. The Lancet 2001;358(9295):1782-83.

\section{Publisher's Note}

Springer Nature remains neutral with regard to jurisdictional claims in published maps and institutional affiliations.

Ready to submit your research? Choose BMC and benefit from:

- fast, convenient online submission

- thorough peer review by experienced researchers in your field

- rapid publication on acceptance

- support for research data, including large and complex data types

- gold Open Access which fosters wider collaboration and increased citations

- maximum visibility for your research: over $100 \mathrm{M}$ website views per year

At $\mathrm{BMC}$, research is always in progress.

Learn more biomedcentral.com/submissions 